\title{
Institutional Divergence of Digital Item Bank Management in Bureaucratic Hybridization: An Application of SSM Based Multi-Method
}

\author{
Nur Muhammaditya ${ }^{1}$. Sudarsono Hardjosoekarto ${ }^{1} \cdot$ One Herwantoko ${ }^{1}$. \\ Yulia Gita Fany ${ }^{1} \cdot$ Mahari Is Subangun ${ }^{1}$
}

Accepted: 11 October 2021 /Published online: 1 November 2021

(C) The Author(s), under exclusive licence to Springer Science+Business Media, LLC, part of Springer Nature 2021

\begin{abstract}
This study aims to analyze institutional divergence of Beckert (2010) by measuring the reframing of three constitutive principles of Digital Weberian Bureaucracy (DWB). In contrast to the studies by Gaus et al. (2017), Sofyani et al. (2018), Muellerleile and Robertson (2018), Turner et al. (2019), and Meilani and Hardjosoekarto (2020), this study explores normative and mimetic mechanisms resulting in the mixed pattern of public administration (Traditional Public Administration (TPA), New Public Management (NPM), and Post NPM), focusing on the transformation of Digital Era Governance (DEG). Employing Soft Systems Methodology (SSM) by Reynolds and Holwell (2010), combined with Text Network Analysis (TNA) by Segev (2020) and Social Network Analysis (SNA) by Borgatti et al. (2014), this study shows the micro dynamics of relationships between actors, the meso dynamics of organizations, and the absence of regulations at the macro level, all of which lead to institutional divergence in the form of fully hybrid governance (as proposed by De Waele et al. (2015)) that is also caused by normative and mimetic mechanisms. Complementing the study of DWB, this study suggests that computer literacy and programming languages are essential to be improved by future bureaucrats as social actors to achieve the success of digital transformation.
\end{abstract}

Keywords Institutional divergence $\cdot$ Bureaucratic reform $\cdot$ Hybridization $\cdot$ Digital era governance $\cdot$ Soft systems methodology $\cdot$ SSM based Multi-Method

Sudarsono Hardjosoekarto

soekarto@ui.ac.id

Nur Muhammaditya

nur.muhammaditya@kemdikbud.go.id

1 Department of Sociology, Faculty of Social and Political Sciences, University of Indonesia, Jakarta, Indonesia 


\section{Introduction}

Various studies of bureaucratic hybridization (a combination of different administrative models) generally focus on three aspects, namely: the power of isomorphism, the desire for organizational change, and organizational resistance to change, as seen in the studies by De Waele et al. (2015), Simonet (2015), Berg and Pinheiro (2016), Correia and Denis (2016), Khodachek and Timoshenko (2018), Breit et al. (2018), Yildızcan and Bayraktar (2019), Donina and Paleari (2019), Xiaolong and Christensen (2019), and Tian and Christensen (2020).

Observing the development of these various studies, it is quite surprising that digital era governance (DEG) has not yet become the locus or context of analysis in the studies of bureaucratic hybridization. In fact, a number of studies indicate that digital transformation is an important strategy to improve service, increase customer engagement, streamline organizations, and create new business processes (Curtis 2019). In Asia, Xu et al. (2017) study the use of big data in libraries in China, while Matsuoka et al. (2020) examine digital hypertension in Japan. In Europe, Möllers (2021) analyzes cybersecurity to increase state legitimacy as well as form a new national identity in Germany, while Rogiers et al. (2020) explore the downsizing of organizations and public servants through a digitalization strategy in Belgium. Furthermore, Garg and Norman (2021) investigate the acceleration of the use of digital technology in facing the Covid 19 pandemic in America.

In the context of Indonesia, studies of bureaucratic hybridization related to DEG are scarce. On one hand, such studies tend to focus on the patterns of public participation without observing the further use of digital technology, as examined a study by Turner et al. (2019). On the other hand, they tend to focus on cultural barriers of bureaucrats to digital-based work completion, as discussed in the studies by Heeks (2002), Sulistiyani and Susanto (2018), and Surjana et al. (2020).

In our opinion, correlating the phenomenon of bureaucratic hybridization with the DEG concept is important when facing the reality of bureaucracy in Indonesia. Sari et al. (2018) and Muliawaty et al. (2019) show the indications of bureaucratic hybridization due to the massive use of digital technology and big data among incompetent and unprofessional bureaucrats or apparatuses with great technological gaps. This suggests the impossibility of discussing the current bureaucratic hybridization in Indonesia without relating it to DEG. However, we observed that such study remains affected by isomorphism in the sense that digital technology will encourage institutional homogenization towards a fully digital bureaucracy. In this understanding, bureaucratic hybridization is temporary and will gradually become fully digital.

In contrast, we observed that the use of digital technology in the bureaucracy in Indonesia also creates institutional divergence. Hybridization in this regard will not shift into fully digital but rather forming variations according to the coercive, normative, mimetic, and competitive dynamics of the organization. One form of institutional divergence occurs in digital item bank management. Thus, this study aims to answer the following questions: How is institutional divergence in the management of digital item bank in the context of digital-hybrid bureaucracy in Indonesia? How do the normative and mimetic aspects institutionally impact intelligent efficiency, sizing up objectivity, and remotely rational of the bureaucracy? The measure of achievement in this study is the reframing of three concepts of constitutive principles of DWB.

We briefly described digital item bank in the next section. Consequently, we described literature review, methodology, discussion, and conclusion. 


\section{Digital Item Bank}

One of the efforts of the Ministry of Education and Culture of the Republic of Indonesia in bureaucratic digitalization is evident in digital item bank management program popularly named Sistem Inovatif Aplikasi Penilaian (SIAP) that has been started since 2016. In this regard, digital transformation is carried out to anticipate the need for innovative items other than multiple choices developed by OECD (2018) to measure the national competence of final level students in the national exams at the levels of elementary school (SD) and secondary school (SMP and SMA). This system thus far has been computerized, yet not supported by an innovative digital item bank that is easily accessible and integrated into the assessment system (Pakpahan 2016). The leader of item bank initiates an organizational overhaul to digitize item bank into an application. Digitizing the item bank is not only a mere shift from paper-based to computer-based, but also a shift from professionals to data scientists (Muellerleile and Robertson 2018). Bureaucrats are faced with big data of item bank that have certain characteristics and management to select authors/revisers in addition to the right items.

However, the development of digital item bank management shows indications of hybridization. It is evident from the management of activities based on outputs in the form of units of activities that is a characteristic of NPM, yet the management uses digital devices such as servers, cloud, and internet with outsiders that is a characteristic of Post NPM. Therefore, we selected this case since it can represent bureaucratic digitalization in Indonesia that is relevant to be explored, particularly from the point of view of institutional divergence.

\section{Literature Review}

\section{Institutional Divergence}

The concept of institutional divergence by Beckert (2010) exists as a critique of the concept of isomorphism (DiMaggio and Powell 1983). In this context, Beckert (2010) criticizes that institutional change does not only produce homogeneity, but also divergence, even though the mechanisms are similar, namely: coercive, normative, mimesis, and competitive (Beckert 2010).

These mechanisms are briefly described as follows. First, coercive divergence is driven by the aspect of power outside the organization preventing organizational structure from leading to isomorphism (homogeneity) with certain goals. In this context, organizational leaders at the local level as well as organizational members can find a critical juncture to negotiate. The rules and regulations introduced into the organization are faced with the existing institutional conditions of the organization, causing the dynamics between them to generate institutional divergence. The second mechanism is normative divergence or attraction in the words of Beckert (2010). In this mechanism, divergence arises because of differences in normative and cognitive frameworks where the current models are evaluated in such a way to discover an appropriate model of institutional change. Third, mimetic divergence in which the organization responds to how strong the influence of the legitimacy of the referral organization. Divergences arise because of the absence of an obligation to be 
similar due to weak legitimacy or only partial values appropriate to the external organization or the strong culture of the original organization.

\section{Digital Weberian Bureaucracy}

According to Muellerleile and Robertson (2018), DWB is a change in modern bureaucracy of Weber driven by the digital machines as a perfect example for bureaucrats. Currently, Indonesia is entering the DWB phase as seen from the increase in digital transformation through the use of big data, digital code, and algorithms in both private and public sectors (Muliawaty et al. 2019). Bureaucracy moves from the framework of paper in motion towards data in motion. Digital infrastructure transforms code into algorithms that are elaborated on a platform where digital footprints substitute material archives. In addition, data scientist replaces expert (Muellerleile and Robertson 2018; Meilani and Hardjosoekarto 2020). Bureaucrats who are adaptive to technology will easily master the reframing of the three principles of modern bureaucracy of Weber (1978), rearranged by Muellerleile and Robertson (2018) into DWB.

First, intelligent efficiency is the result of an expansion of digitalization resulting in automation of machines and the internet into real time that does not require human decisions to maintain its further efficiency. Second, sizing up objectivity is the neutral assessment of the results of automated applications and platforms that massively use separate algorithms that do not require human decisions to maintain its further objectivity, avoiding political interests. Third, remotely rational is the transformation of social structures in the digital world codified through servers and cloud computing, transforming into an account and user id to form a new digital reality that remains monitored and controlled remotely.

In the viewpoint of DWB, bureaucratic transformation is in line with DEG from the aspect of public administration that requires the principles of reintegration, comprehensive needs-based, and digitalization (Dunleavy et al. 2006; Margetts and Dunleavy 2013). Government collaboration, including application integration, big data, and access is a major issue of reintegration that must be seen as the need of organizations for a systemic and comprehensive network instead of impartial. These two aspects are realized through digitalization starting with digital transformation by utilizing the internet, servers, applications, platforms, including artificial intelligence. The intersection of the three aspects of DEG administratively, combined with the characteristics of reframing of the three principles of DWB, will encourage an automatic process towards zero touch technology (ZTT).

\section{Bureaucratic Hybridization}

In general theory of organization, hybridization occurs because it implements a mixture of state and market models (Gulbrandsen 2011). Another view states that public hybridization is a combination of organizational characters between public and private (Gebreiter and Hidayah 2019). Meanwhile, in this study, bureaucratic hybridization is understood as a combination of public administration based on the division of organizational culture by De Waele et al. (2015) consisting of beliefs, design, and control as part of the ideal type of institutional logic from TPA, NPM, and Post NPM as presented in Table 1 (Ugyel 2014; De Waele et al. 2015).

Beliefs refer to the abstract level of the organization that underlies bureaucrats to act on hierarchy (TPA), market (NPM), or network (Post-NPM). Design is the actualization 
Table 1 Hybrid configuration

\begin{tabular}{|c|c|c|c|}
\hline Hybrid configuration & Beliefs & Design & Control \\
\hline \multicolumn{4}{|l|}{ Level 1} \\
\hline Non-Hybrid & Hierarchy & Specialization & Processes \\
\hline \multicolumn{4}{|l|}{ Level 2} \\
\hline Partially hybrid, TPA dimensions dominating & Hierarchy & Specialization & Outputs \\
\hline Partially hybrid, NPM dimensions dominating & Market & Specialization & Outputs \\
\hline Partially hybrid, Post NPM dimensions dominating & Network & Delegation & Outcomes \\
\hline \multicolumn{4}{|l|}{ Level 3} \\
\hline Fully Hybrid & Hierarchy & Participation & Outputs \\
\hline
\end{tabular}

Adapted from De Waele et al. 2015

of actions in the work completion based on specialization (TPA), delegation (NPM), or participation (Post-NPM). Control is understood as how organizational goals and strategies are defined, whether prioritizing processes (TPA), outputs (NPM), or outcomes (Post NPM) (De Waele et al. 2015). In the context of this study, hybridization by De Waele et al. (2015) is theoretically related to the institutional divergence of Beckert (2010) that is measured through the dimensions of intelligent efficiency, sizing up objectivity, and remotely rational as the characteristics of DWB (Muellerleile and Robertson 2018).

\section{Methodology}

Most of the doctoral dissertations and master theses under the supervision of Hardjosoekarto applied Action Research-based SSM, such as those by Yovani (2013), Hadiyanto (2013), Ediyono (2013), and Pinora (2014). A small number of others use multimethodology, such as those by Wilopo (2013) and Kusumastuti (2013). However, we used the term multi-method in reference to Mingers (2001) and Stephens et al. (2009), namely the incorporation of a positivist paradigm in SSM in the form of a combination of two or more research methods.

The first reason for using multi-method is the availability of various data. In line with the studies by Hildebrandt and Eom (2011); Larrán et al. (2015); and Diegel et al. (2020) that use organizational narratives and interviews to measure divergence, the measuring instruments used in this study are categorized into macro, meso, and micro. The three complementary levels were chosen because of the access to institutional documents in the form of rules and regulations, information from relevant actors in the form of interview notes, experienced-based organizational observations, and user activity log data in the application. Thus, in line with the interpretive paradigm in SSM, the multi-method combination in the application of SSM in this study was put in the fifth stage as additional new interpretive media.

The second reason is the capability of multi-method to meet the need for research data at the three levels of analysis. In this regard, the advantages of SSM in extracting data at the micro and meso levels can be configured with the advantages of TNA in processing organizational narratives at the macro, meso, and micro levels as TNA is a method that combines content analysis and network analysis (Segev 2020). In previous studies, the use 
of TNA also provides added value in mapping relationships and patterns of information when combined with a grounded theory (Glaser and Anselm 2017).

Meanwhile, the configuration of the SNA method using activity log data, as conducted by Van der Aalst (2007), has the advantage of network visualization that adds insight into user performance in the application, displayed by the position of actors in the structural graph (Mehra et al. 2001; Borgatti et al. 2014). Each relationship between the actors involved in the activities forms centrality in the network (nodes) that can be quantitatively compared. The performance of actors was measured based on the out-degree category, while the activities were measured from the in-degree category. The relationship was then interpreted as performance as well as position in a structural graph to differentiate between the performance of bureaucrats and of users from outside organizations. In this study, TNA and SNA were integrated in the fifth stage of SSM, as shown in Fig. 1.

Generally, the SSM stages conducted are as follows. The first step was to identify the problematic situation at the micro and meso levels. The data were collected using in-depth interviews with the owners of the problem, namely 2 people from the cluster of leader (Head of Division/Coordinator and Person in Charge of Activities (PCA)) at the meso level, 3 people from the cluster of Chief Information Officer (CIO), 2 people from the cluster of field of study as Person in Charge of Material (PCM), and 5 people from the cluster of application developers at the micro level who are involved in organizing the item bank, starting from drafting, authoring, revising, testing, and finalizing items until they are ready to use. In-depth interviews were conducted to explore divergence that occurs in item bank management.

The second step was to enter the problematic situation obtained from the interview and experienced-based organizational observation into the rich picture. In this second step, the data obtained from participatory observation were also added because one of the authors was involved in the mechanism of digital transformation as a member of the cluster of field of study and was in charge of activities. Observational data were

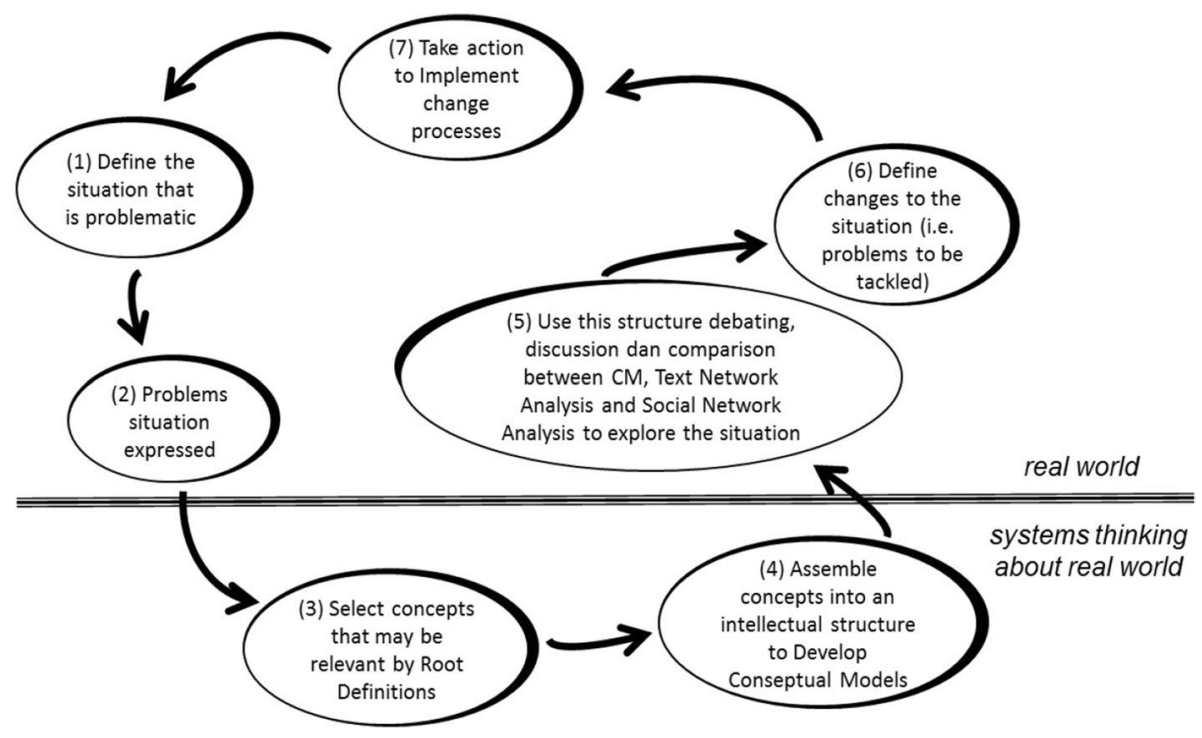

Fig. 1 Multi-method based SSM. Source: (Checkland 2000; Mehra et al. 2001; Van der Aalst 2007; Wilson 2010; Reynolds and Holwell 2010; Hardjosoekarto 2012; Borgatti et al. 2014; Permatasari et al. 2019; Segev 2020) 
obtained from the experience of the author for five years since the application was made in 2016, in addition to its organizational dynamics. The third step was to create a root definition complete with the analysis of Customer, Actor, Transformation, World View, Owner, and Environmental Constraints (CATWOE). Meanwhile, the fourth step was to develop a conceptual model in which the model was measured by 3 Es criteria, namely efficacy, efficiency, and effectiveness.

In the fifth stage, we conducted TNA analysis at all three levels to discover the source of knowledge about digital transformation. TNA data were taken from organizational narratives that, according to Larrán et al. (2015), are in the form of policies and regulations. At the macro level, the data collected were the Government Regulation (PP) No 11 of 2017 and No 17 of 2020, the regulation of the Ministry of Administrative and Bureaucratic Reform (PAN-RB) No 25 of 2020, the regulation of the Ministry of Education and Culture (Kemdikbud) No 11 of 2018 and No 45 of 2019, the report of the Inspectorate General of 2019, Integrity Zone (ZI) towards Corruption-Free Area (WBK) Work Plan by Center for Assessment and Learning (Pusmenjar) of 2018 and 2019. At the meso level, the data collected were documents on technical rules for activities and standard operational procedures for item bank. Meanwhile, at the micro level, the analyzed narratives originate from the results of in-depth interviews (Diegel et al. 2020).

SNA analysis was also carried out in the fifth stage to determine the performance of actors and the types of activities most widely transpired. The data were obtained from the records of daily activity logs of actors involved in digital item bank management using the software. The number of accounts monitored from 2017 to 2020 were 4 accounts of CIO, 22 accounts of PCM, and 126 accounts of actors indirectly involved. The performance of each account was compared through SNA using an out-degree scale. Meanwhile, the activities were compared using an in-degree scale (Mehra et al. 2001; Borgatti et al. 2014). Furthermore, the TNA and SNA methods were compared, discussed, debated with the conceptual model generated in the fourth stage of SSM. The softwares used to perform the TNA and SNA analyses were WORDij and Gephi.

Analysis

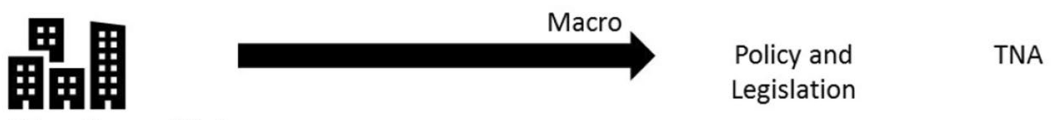

Ministry Education and Culture

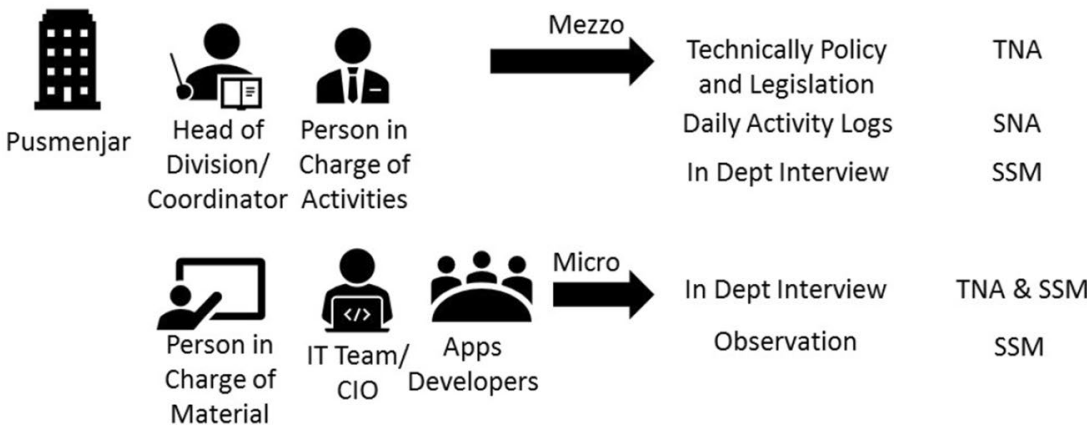

Fig. 2 Identification of data sources. Source: (Checkland 2000; Mehra et al. 2001; Van der Aalst 2007; Wilson 2010; Reynolds and Holwell 2010; Borgatti et al. 2014; Segev 2020) 
The sixth step was to develop recommendations for changes and actions to resolve the problem based on the results of comparison and debate in the fifth stage. The seventh stage was to propose a policy as a practical novelty to be applied by policy makers and related stakeholders in the digital item bank management. The data sources for each level are identified in Fig. 2.

Methodologically, SSM in this study is limited to not being used as a participative process tool (Muluk et al. 2019). The definition of the application is based on the functional dimension of SSM as "a learning process aiming at improvement and attempting to solve complex and problematic human situations" (Tsoi 2004). In such a context, Brocklesby (1995) also states that SSM follows an interpretive tradition and is generally used as an epistemological tool that allows greater understanding and appreciation of the problematic situation. It is in line with the opinion of Al-Kaabi (2020) refering Pollack (2007), that the SSM is closely related to "interpretive epistemology, inductive reasoning, and exploration, a qualitative technique that emphasizes contextual relevance rather than objectivity".

\section{Discussion}

\section{The Problem of Transformation}

Observed from the results of in-depth interviews, the problem of digital transformation lies at the macro, meso, and micro levels. At the macro level, the problem is the lack of rules. It is conveyed by CIO 1: "There are no certain rules to begin with. What we know is that we work only based on the orders from the leaders". The results of other interviews also show that the institutional rules regarding digital transformation are found at the meso level instead. However, these rules are not always referred to in practice. It is expressed by CIO 3 as follows: "We rarely use the rules directly in practice. Sometimes we don't even use the rules. It is a different practice in the application or in the field. There are numerous changes not contained in the rules".

At the meso level, there is a problem with the limited access to improve competence. In this case, observed from the organizational willingness, there is a desire to be similar to digital item bank management by ETS (https://www.ets.org/) and ACER (https://www.acer. org/au/). It is conveyed by PCA: "We have indeed learned from the development in other countries through short training programs at ACER and Masters and Doctoral degrees with an internship program at ETS". However, only a small proportion of bureaucrats has the opportunity to learn, thus not all of the results can be applied and accepted by members, leading to adaptation according to the institutional capacity. It is in line with the statement of PCA as follows: "We adapt the examples in their countries and how they develop the item banks as a stimulator to develop our own item bank." In line with PCA, PCM also adapts the form of PISA questions as stated in the following: "We are indeed inspired by PISA, though not entirely, as we eventually adapt them for the context of Indonesia".

At the micro level, there are 3 (three) problems. First, the low ability of CIO in terms of programming languages, such as MySQL, ReactJS, Laravel, CK Editor, and PHP, resulting in delegation of work on application to the private sector. It is stated by CIO 1: "We do not have sufficient capabilities for making applications. Thus, we need a third party specialized in making applications". A similar opinion is conveyed by the Head of the Division/Coordinator: "The system development is delegated to the experts of application development. We only provide the content". 
Second, in terms of professionalism, the expertise of PCM is limited to various fields such as natural sciences, social sciences, and linguistics, as conveyed by the Head of Division/Coordinator: "The expertise in fields of study is based on the national exam, namely 25 to 30 fields of study, with similar assessment system. The office, in fact, comprises experts in assessment (psychometrics)". The problem arises when access to digital knowledge through training is not balanced in every field of study. For example, natural sciences are more involved in digital training compared to other fields of study. It results in different competence among different fields of study. Those with access to knowledge have more creativity in completing work, conveyed by the Head of Division/Coordinator as "Creativity in discovering and experimenting what works faster".

Third, in the micro-level interaction, a strong culture in paper-based management still influences the division of tasks, work completion, and decision in application development, becoming an obstacle to achieve good organization as conveyed by PCA. "There may be an old paper-based habit carried out in the application and digitalization". Another influencing cultural practice is patronistic. The term patronistic in this study refers to the definition by Ugyel (2014) and Turner et al. (2019), namely a system dominated by loyalty from power of accountability in the form of mutually beneficial and reciprocal personal relationships by providing services according to the needs of the patron. This behavior is obtained from the results of experienced based organizational observations, such as positioning younger CIOs and PCMs as clients to work harder to help Patrons from older groups adapt to digital transformation, as conveyed by CIO 1. "It is common for those with higher rank to order the younger to work harder." Young CIOs and PCMs are willing to work more in order to score in an assessment of good performance that will affect their involvement in future activities. The additional burden outside item bank management renders CIOs unable to fully concentrate on digital development software alone. It is different from the successful digital item bank management portrayed by Dwivedi et al. (2021) or OECD (2018).

\section{The Rich Picture of the Problem}

The second stage translates the unstructured problematic situation into a network of information in the form of relationships among images or rich picture (Reynolds and Holwell 2010). Institutionally, the Ministry of Education and Culture and the regional Department of Education have rules for organizational governance at the macro level. On the other hand, external organizations also influence organizational dynamics through training, formal education, item forms, and examples of digitalization. Two sources at the macro level will experience dynamics at the meso level in the form of technical rules for activities and SOP for Item Bank. The problem at the macro level is the absence of specific rules regarding digital transformation while the problem at the meso level is weak legitimacy of external organizations in dealing with normative mechanisms produced by leaders and members of the organization at the micro level in the form of a desire for applications that ensure security and reach authors throughout Indonesia using an online system. Leaders cannot achieve it without the assistance of PCA, CIO, PCM, and application developers as directly involved actors.

The dynamics at the micro level then form a mutual understanding that digital transformation is necessary to solve problems of paper-based management, such as the obligation to travel on business trip to obtain the items, management limited to certain space, cannot be conducted outside without close supervision by the administrator, and the increasingly 
need for paper every year in accordance with the increase in the total outputs of the organization. Problems of paper-based management have an impact on the uncontrollable writing load.

In an effort to solve the problems of digital transformation, leaders and CIO involve professional application developers with programming expertise. A problem arises when feedback on the application can be given only if the application has been finished or used. The improvement results in three core applications in SIAP that are then integrated into a SIAP platform in the digital area. All activities on paper are transformed into a digital system that relies on cloud infrastructure, the internet, and servers to replace the requirements of space on the paper model. In the aspect of digitalization, the parties knowing the information technology among the groups of directly-involved actors are CIO. It renders the function of the CIO dominant in assisting the administrative needs of digital item bank. The rich picture is presented in the following Fig. 3.

\section{Adjustment of Concept through Root Definition}

The problem obtained from the real world needs to be formulated in the actual world in two stages. The first stage is to select and name a Human Activity System from Human Activity Systems. The second stage is to compile a conceptual model of the selected Human Activity System. The selection is functioned to answer the questions "What is the institutional divergence in digital item bank management in the context of digitalhybrid bureaucracy in Indonesia?" and "How do mimetic and normative aspects institutionally affect intelligent efficiency, sizing up objectivity, and remotely rational of bureaucracy?" The application of SSM in this study is limited to answer only the second

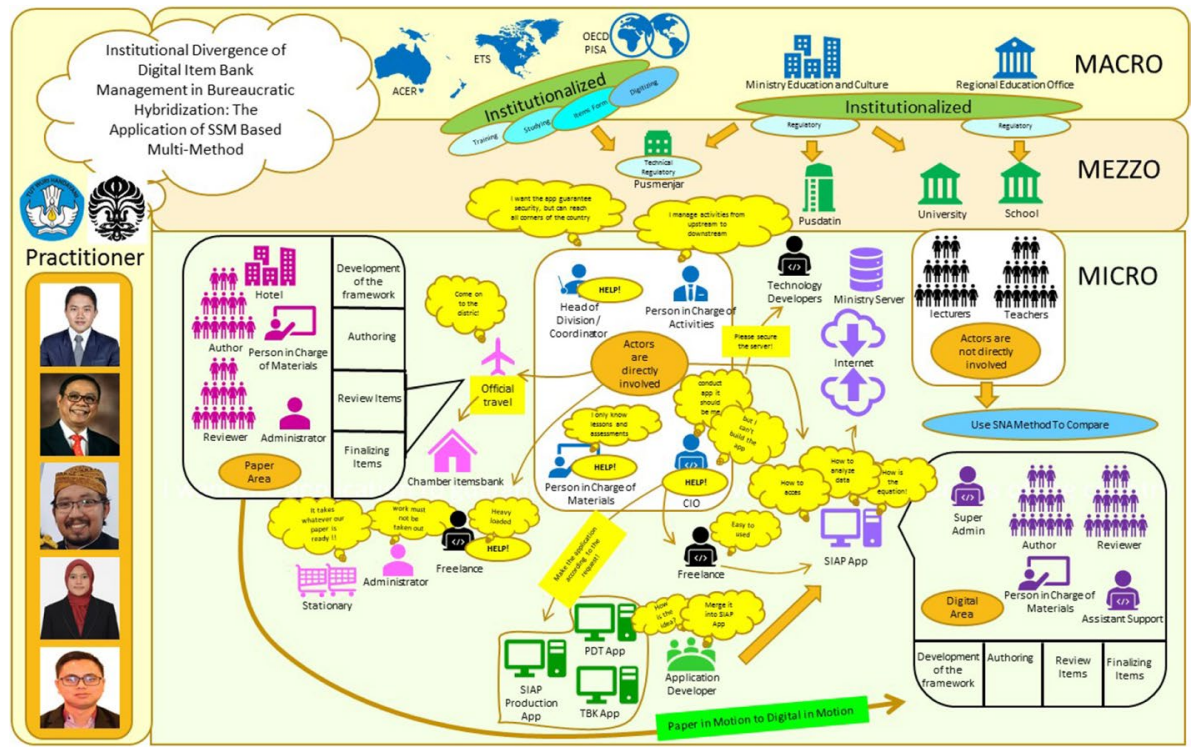

Fig. 3 Rich Picture based on the problematic situation. Source: Interview with the cluster of owner of the problem addressed 
question, focusing on SSM as an empirical interest to provide real improvement solutions to organizational problems.

The technique used in identifying Human Activity System in the form of PQR aiming to answer what is done (P), how to do it $(\mathrm{Q})$, and why it is done as an objective $(\mathrm{R})$, in this regard sourced and carried out by the cluster of leaders (Kareborn 2004). Using the PQR formula by Checkland and Poulter (2006), the root definition of the management of digital item bank is named as follows:

The desire and action for reintegrating organizational resources through a digital approach in the form of management of more flexible item development with innovative items according to community demands (P), using an application in the form of a platform that changes the management mechanism to digital data (Q), to ensure that digital transformation on DEG that pay attention to the needs of the organization can be achieved holistically (R).

The Root Definition is the constructed from the results of interviews with the leaders as the owner of the problem. Meanwhile, PQR is carried out by the cluster of leaders as a decision to implement digital transformation. To test the accuracy of selecting and naming the Human Activity System, the CATWOE analysis method was used in the form of analysis of the elements of Customers, Actors, Transformation, Weltanschaaung (Worldview), Owners, Environment (Hardjosoekarto 2012; Hardjosoekarto et al. 2013; Permatasari et al. 2019). In the development of item bank, CATWOE is described at Table 2.

\section{The Ideal Model of Transformation of Item Bank}

The depiction of the conceptual model is preceded by describing the activity carried out, elaborated with a theoretical view starting from the root definition that has been previously formulated. This activity is item development, and aiming at DEG, it needs to undergo an integrated digital platform. In its application in the real world, it is hindered by low competencies of social actors in compensating for uneven technological developments, in addition to an old organizational culture that has not been able to adapt to changes. Encouraged by the opinions of the owners who place high trust in digital mechanisms, the conceptual model offered to systemically solve the problems in the development of digital item bank to achieve DEG is presented in Fig. 4. The first important point in the conceptual model is that rules and regulations institutionally have dynamics that cannot be simply applied in digital transformation. Actors have their own definitions based on knowledge that in a normative mechanism influence organizational policies at the micro level. Thus, a conceptual intervention in the form of more concrete and coercive rules and regulations is necessary. Furthermore, based on the pattern of ACER item bank development in the interview data, the second important point is to increase the ability of CIO mimically to be able to build their own application system. Third, still related to the mimetic process, the competence of PCM needs to be improved to be able to perform data analysis as conducted by data scientists and data engineers. The application of these three points will have a conceptual impact on intelligent efficiency, sizing up objectivity, and remotely rational as shown in Fig. 4.

It is necessary to identify whether the conceptual model meets the five elements of criteria, namely efficacy, efficiency, effectiveness, elegance, and ethicality (Hardjosoekarto 2012; Hardjosoekarto et al. 2014; Permatasari et al. 2019). However, this study only discussed three elements, namely efficacy that observes the extent to which the changes provide benefits, efficiency that takes into account the minimum use of resources, and 


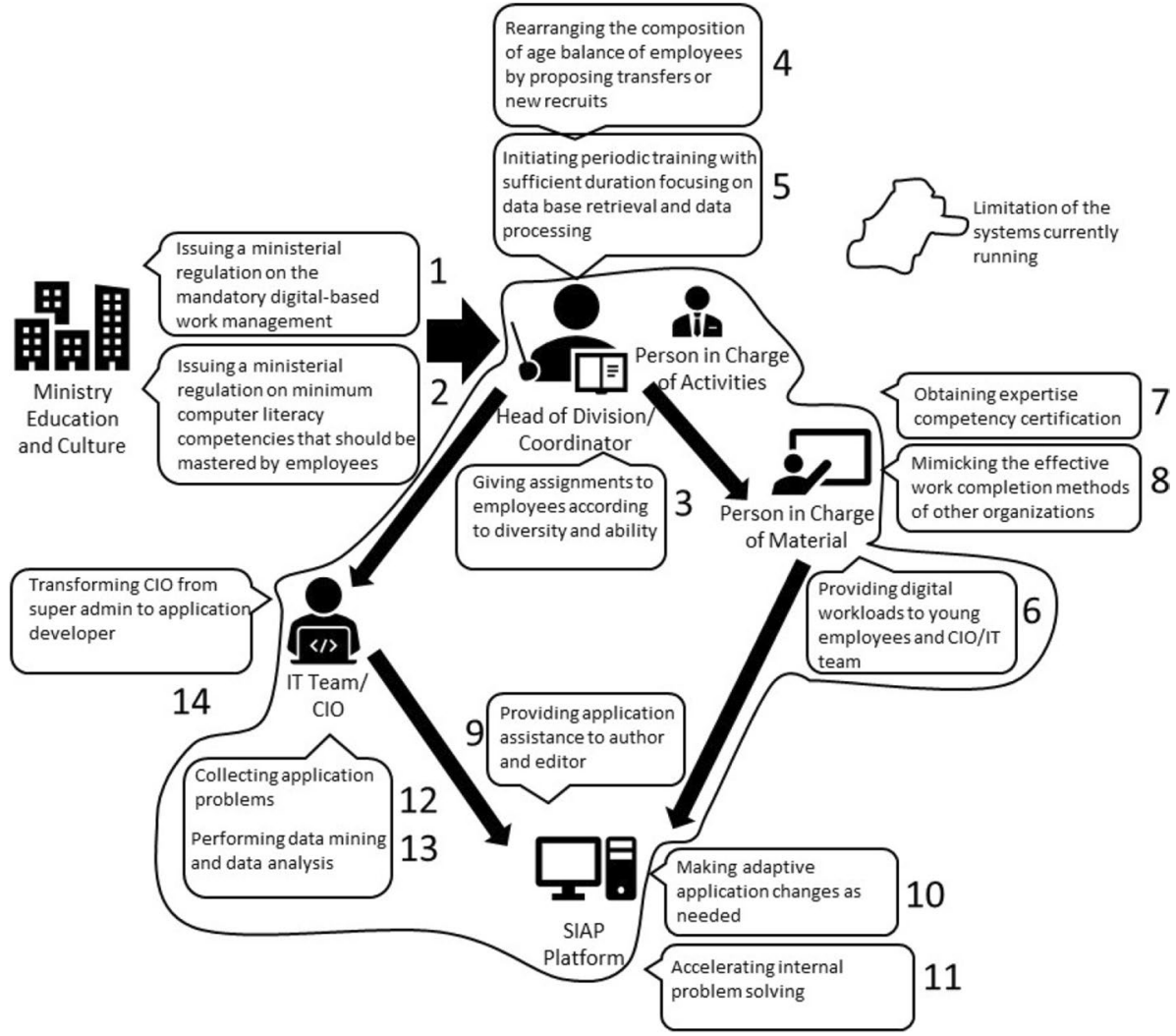

Fig. 4 A conceptual model for the development of digital item bank in DEG. Source: A conceptual framework based on data, theory, and logic to answer the second research question, namely how normative and mimetic divergences affect intelligent efficiency, sizing up objectivity, dan remotely rational

effectiveness that considers optimal utilization of time, as shown in Table 3. Ethicality and elegance are not taken into account based on the consideration that the transformation is

Table 2 An analysis of CATWOE of human activity system

\begin{tabular}{|c|c|}
\hline Customers & $\begin{array}{l}\text { The Ministry of Education and Culture, the Office of Regional Education, Schools, } \\
\text { Teachers, and Exam Participants }\end{array}$ \\
\hline Actors & Leaders, Persons in Charge of Material, CIO \\
\hline Transformation & $\begin{array}{l}\text { DEG transformation addresses organizational needs in a holistic manner through reinte- } \\
\text { gration of organizational resources through a digital approach }\end{array}$ \\
\hline Worldview & The digital mechanism is able to integrate the needs of the development of item bank \\
\hline Owners & The Ministry of Education and Culture \\
\hline Environment & $\begin{array}{l}\text { The need for competency and adaptive organizational culture according to the transfor- } \\
\text { mation }\end{array}$ \\
\hline
\end{tabular}

It is part of logic-based stream of analysis 
Table 3 Testing the 3E of criteria (Hardjosoekarto 2012; Hardjosoekarto et al. 2013; Permatasari et al. 2019)

\begin{tabular}{ll}
\hline Efficacy $(1 E)$ & $\begin{array}{l}\text { Increasing employee competence, not only at an ideal level, but also at } \\
\text { practical level at work. }\end{array}$ \\
\hline Efficiency $(2 E)$ & $\begin{array}{l}\text { Organizational capabilities in accordance with the needs of digital work to } \\
\text { streamline coordination lines }\end{array}$ \\
Effectivity $(3 E)$ & The model will successfully optimize bureaucratic resources more quickly.
\end{tabular}

It is part of logic-based stream of analysis

appropriate in a morally good organization and focuses more on the function of the model (Kotiadis et al. 2013).

\section{Discussion}

\section{Comparison of Formal Questions Regarding Intelligent Efficiency, Sizing up Objectivity, and Remotely Rational Using a Conceptual Model}

The conceptual model is only a means to achieve the epistemological model (Hardjosoekarto 2012; Hardjosoekarto et al. 2013; Permatasari et al. 2019). An important point is how a coherent model structure is compared with the worldview to increase the understanding of the real world. Checkland (2000) shows four ways in making comparisons, one of which is through formal questions. In formulating formal questions, a matrix derived from the conceptual model is used (see Table 4).

The comparison of formal questions shows that the aspects of intelligent efficiency, sizing up objectivity, and remotely rational as the characteristics of DEG bureaucracy in the case study of digital item bank are still far from expectations. Big data in the application is easily accessible in real time, but the capability to perform data analysis is not mastered by all actors directly involved in the management to produce fast and efficient policies. Due to the lack of competence in digital data analysis, the aspect of efficiency achieved is only at the surface level, namely saving paper, can be conducted anywhere, and not limited by time. Observed from the aspect of sizing up objectivity, the autonomous use of Big Data has not yet become the basis for organizational decisions. Instead of producing statistical quantification of data-based governance, the divergence of professionalism of PCM that relies data mining and data analysis on CIO has the potential to create objectivity bias as data sources are not searched and analyzed by themselves as required, but have been provided without professional intervention. Observed from the aspect of remotely rational, digitalization resulting in immediate access has created a new structure in the application. In the case of digital item bank, the CIO as the super admin has a great amount of authority and is separate from the formal organizational structure, while professionals experience lack in control. The new rationality creates a gap between professionals and the mechanism of digital work. Thus, the intelligent, sizing up, and remotely characteristics need to be improved according to the comparative table in the form of training, education, and expertise certification for PCM as the backbone of the successful development of digital item bank. 


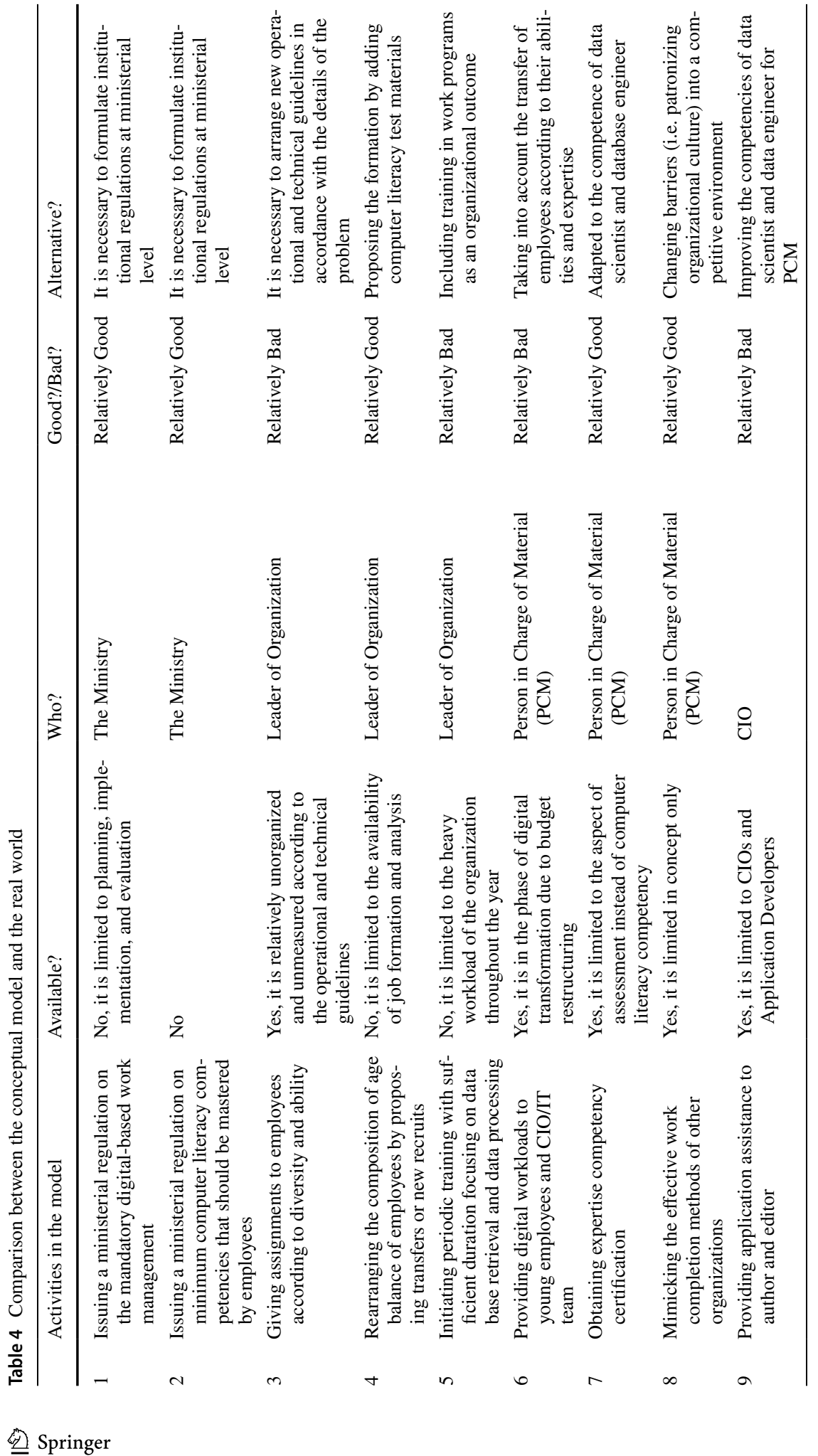




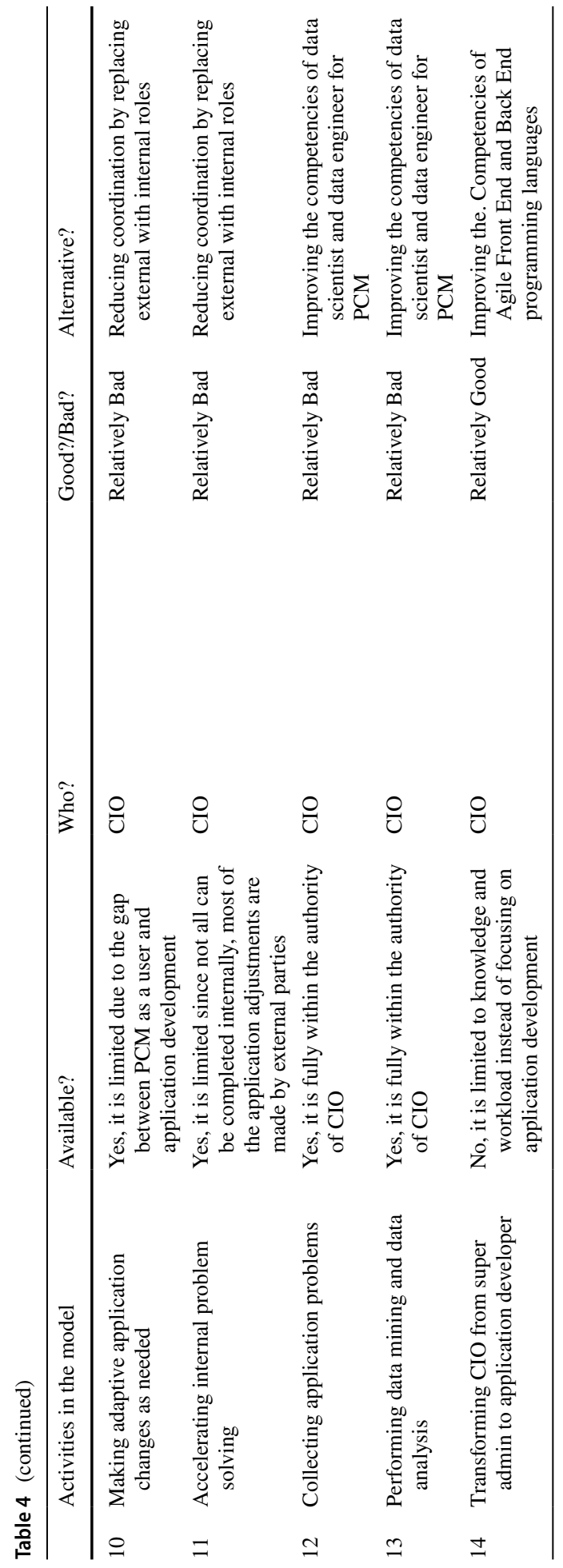




\section{TNA from Organizational Narratives and SNA from Daily Logs}

In accordance with the methodological framework that categorizes this study as SSM based on multi-method, the comparison of the actual ideal model with the real world is also employed with TNA (Danowski and Riopelle 2020; Segev 2020) and SNA (Mehra et al. 2001; Van der Aalst 2007; Borgatti et al. 2014). The data to be analyzed are organizational narratives that, according to Diegel et al. (2020), in the form of institutional rules that affect organizational governance and activity log data in using the application. Based on data sources, TNA is divided into macro, meso, and micro levels. The results of data processing of institutional rules are presented in Fig. 5.

\section{Macro}

There are four large clusters comprising the network: purple for bureaucratic reform, blue for the implementation of program evaluation, pink for financial statements, and green for various organizational functions in the education sector. Based on the data of modularity, betweeness centrality, and degree, the meaningful words in each cluster indicate that institutional administration is still in NPM phase, as evidenced by the TNA structure in the blue cluster, namely the implementation of program evaluation measured from the results of activities and budget. The finding on the blue cluster is strengthened by the green cluster that research and development activities are limited to carrying out institutional tasks internally. Thus, bureaucratic reform in the purple cluster is more interpreted as the procedures for implementing output-based activities that measure the performance achievements from the financial statements of the organization as illustrated in the pink cluster. On the other hand, the word digital transformation does not appear in all clusters, indicating the low attention of the elite to digital reform at the macro level.

\section{Meso}

In line with the low level of regulations on digital transformation at the macro level, the regulations on technical institutional activities at the meso level show similar picture. Based on the analysis of modularity, betweeness centrality, and degree, there are four clusters as follows: pink that regulates the examination activities, purple that regulates the implementation of the trials, blue that regulates the implementation of the item bank, and green as the cluster of location, namely the education assessment center. These four colors are in accordance with the results of analysis at the macro level, not positioning digitalization as a technical requirement that needs detail regulations. This finding is in agreement with the results of the interview that digitalization is only a tool and a way of completing work, also affirming that digital item bank remains in the NPM phase.

\section{Micro}

The low aspect of digital transformation at the macro and meso levels is inversely proportional to TNA at the micro level. Based on the analysis of modularity, betweeness centrality, and degree, there are two large groups of cluster represented by green as the data group and purple as the application group. Both clusters reflect the text narrative of digital transformation. Application is the biggest theme in the interview followed by the data, proving 


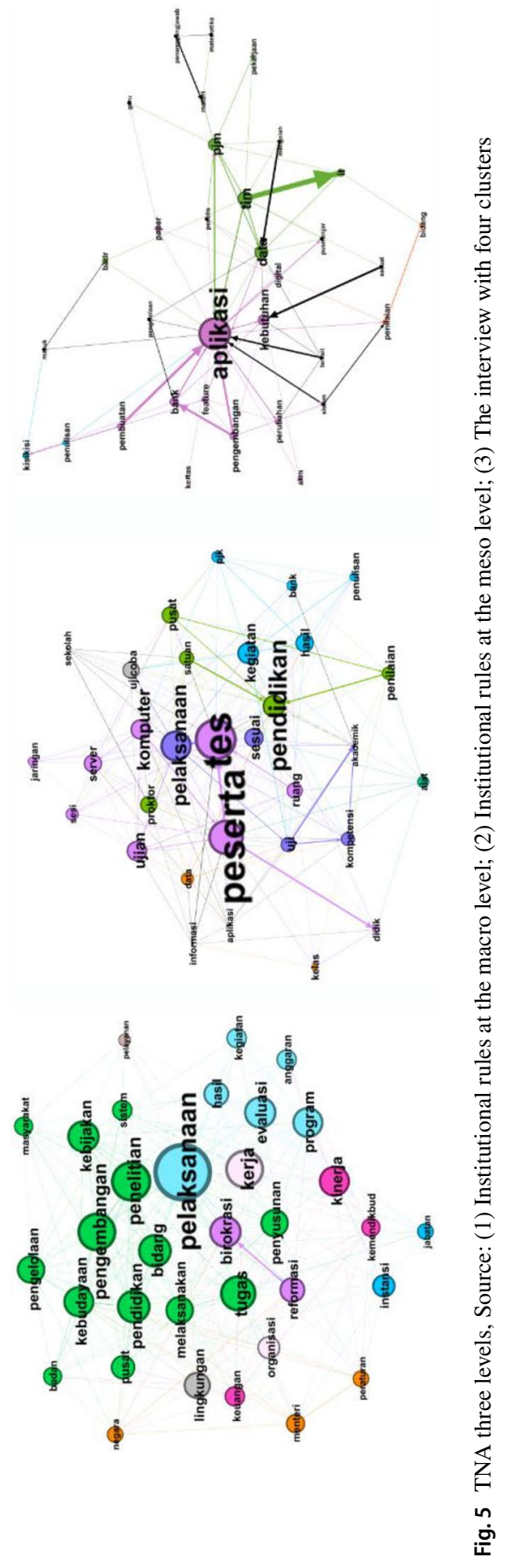




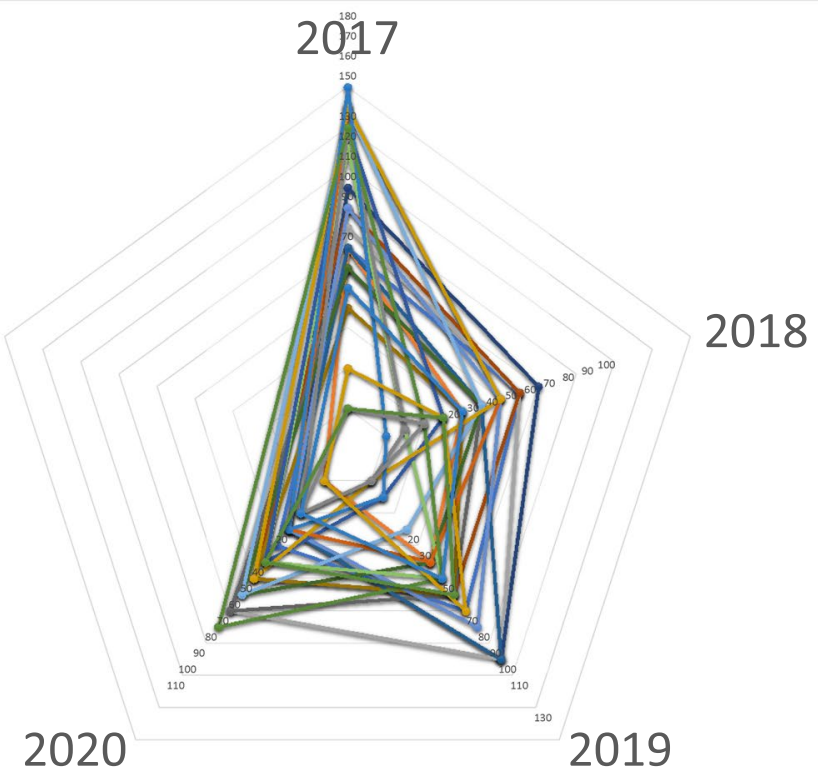

Fig. 6 Comparison of the Performance of CIO, PCM and Actor indirectly involved. Top Performance (CIO), Moderate Performance (Author/Reviewer), Low Performance (PCM). Source: SNA processing data using an out-degree scale

that the digitalization of organizational governance is a central issue. The differences in the position of digitalization at the macro, meso, and micro levels affect the differences in the normative mechanism, that the actions of actors at the micro level are not regulated institutionally, but observed as a policy product that is expected to change.

The results of TNA at each level show similar evidence that the aspects of intelligent efficiency, sizing up objectivity, and remotely rational are still in the NPM phase. "Big data" is only shown at the micro level with the value of betweeness centrality of " 0 ", meaning that it is not significant to be referred to as the main text of organizational governance. Having big data without processing will not result in data-based policies and at the same time it negates the position of intelligent efficiency and sizing up objectivity. On the other hand, the role of CIO illustrated at TNA at the micro level confirms that remotely rational in the form of repetitive process through digital algorithms is also not manifested. It means that data processing is not urgent and frequently carried out by CIO.

\section{Performance Based on Daily Logs}

User activity in the application is recorded daily into log data and analyzed from 2017 to 2020. The logic of measurement refers to Mehra et al. (2001) and Borgatti et al. (2014) that each activity in the application will form a structural position. More access to certain activities in the application will confirm the position of the nodes in a structural position as well 
as increase the performance in application management. Observed from the comparison of the number of actors involved from structural of the network, it is evident that activities in 2017 and 2018 have a larger structure than activities in 2019 and 2020. In correlation with the structure of actors in the application and based on the data obtained from the interview, one of the reasons is the change of leadership at the macro level, the outputs of the activities, and organizational goals at the meso level.

The out-degree scale is used to measure the performance of the actors involved as shown in Fig. 6. The results show that CIO occupies the top position as the actors with the highest performance compared to the other two groups. Meanwhile, writers and revisers from outside the organization have better performance than PCM that occupies the lowest position in terms of performance. Referring to this differences, it can be concluded that digital transformation cannot simultaneously provide positive changes to organizational performance. Bureaucrats as actors of transformation need to be encouraged to be adaptive and competitive with digital tasks by increasing their competence through training, especially in the functions of data scientists and data engineers.

The in-degree scale is used to measure the activities carried out. An interesting finding on this scale is that rating is the lowest activity accessed by PCM, even though rating is a feature assigned by the leader to PCM to provide an assessment of each item inputted, affecting the assessment of authors/revisers. Data rating can be quantified to show the quality of writers and revisers as part of the big data of item bank that can be processed automatically when the data are available correctly. The low rate of rating indicates the inaccuracy of the quantity and quality of the data and shows that PCM does not control the quality of the items through the application. It also indicates that the data of authors and revisers originate from the justification of PCM.

Observed from the aspects of intelligent efficiency, sizing up objectivity, and remotely rational, SNA data reveal that different performance of actors in the application leads to normative mechanisms. The different performance of CIO and PCM is not only caused by knowledge about information technology, but also determined by the age difference, the professionalism of various fields of study, individual creativity in dealing with problems, and the patronistic culture that places younger PCM as the motor of digital transformation.

\section{The Comparison of Results of Multi Method and DWB Principles}

The results of the three methods (formal questions, TNA and SNA) are measured in the three categories (intelligent efficiency, sizing up objectivity, and remotely rational) in the DWB framework as presented in Table 5.

\section{Recommended Actions}

Stages 6 and 7 in SSM are recommendations for changes and actions to solve problems based on the results of comparisons and debates as shown in Table 6. Based on the comparison of multi-method, digital transformation in the item bank has not yet reached the ideal degree of intelligent efficiency, sizing up objectivity, and remotely rational. The low ability of actors is influenced by institutional divergence, proving that the alternatives in the fifth stage are significantly relevant to apply. This view is supported by the evidence of the results of TNA at three levels, stating that almost all of the proposed 


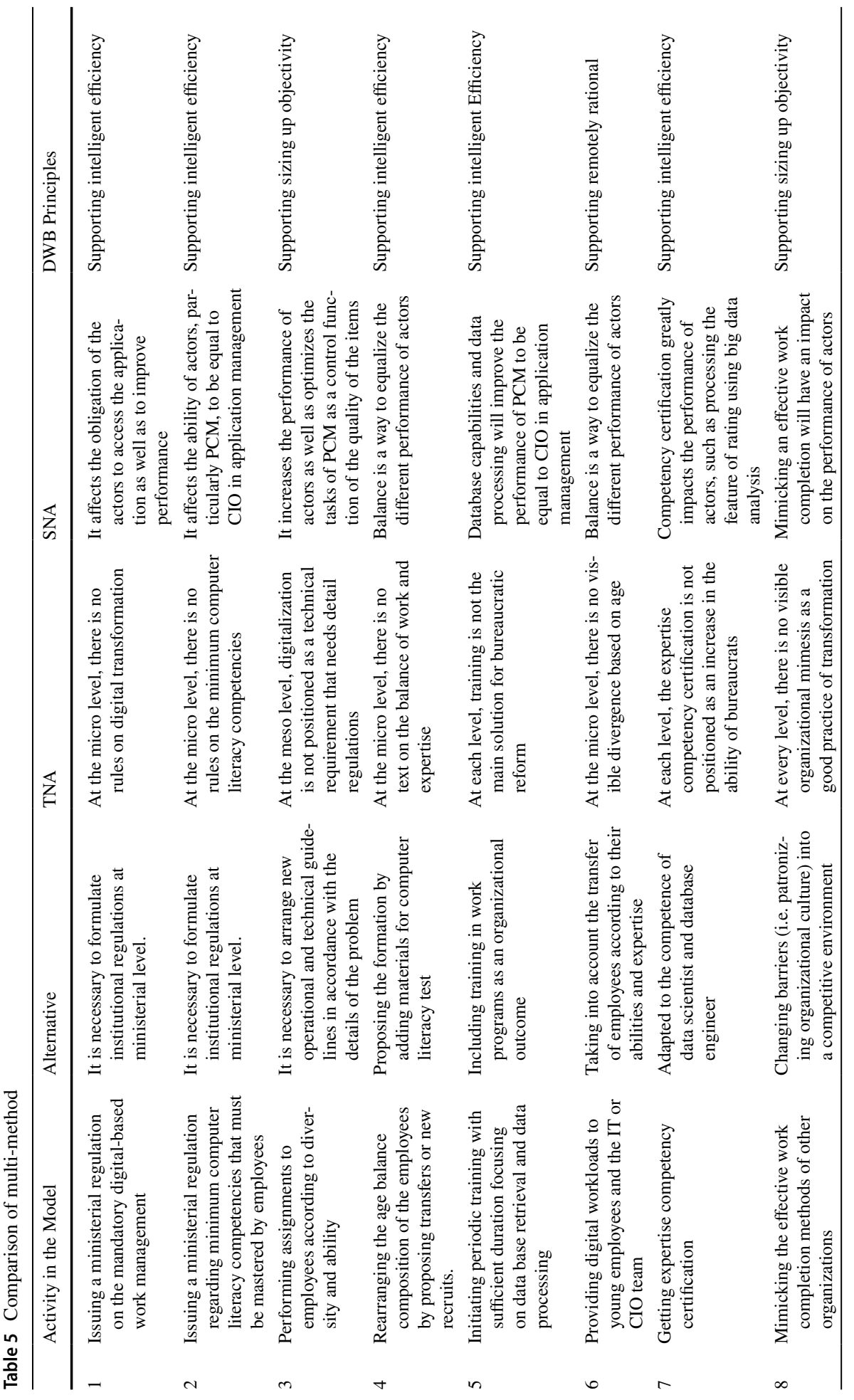




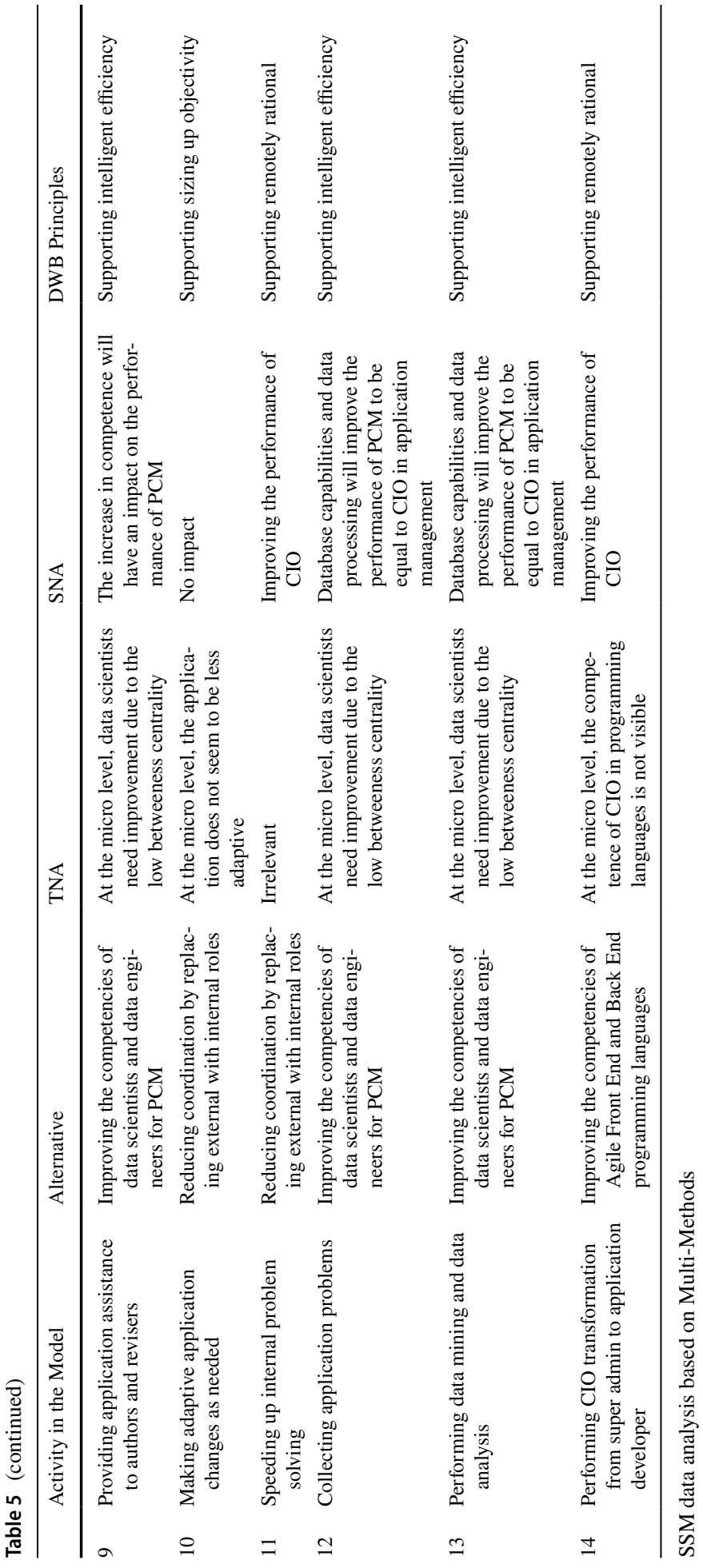




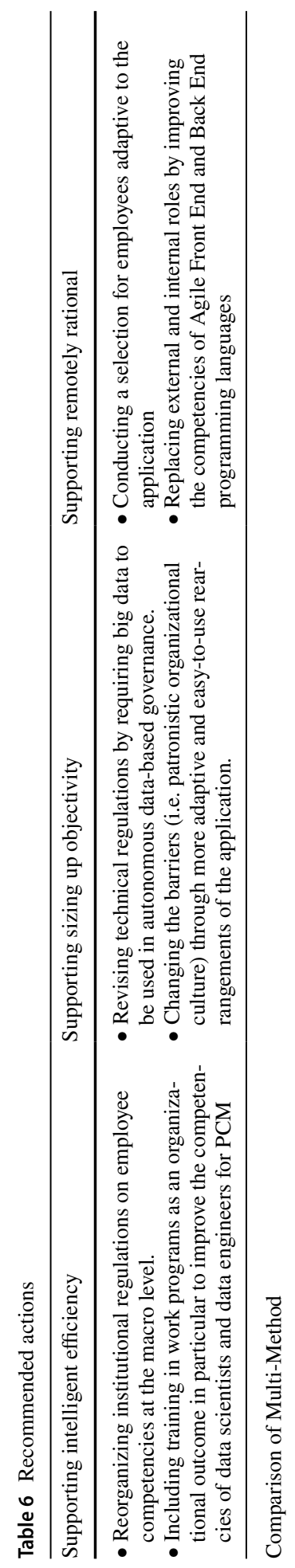


materials are not depicted in the text network except for data scientist, even though the value of betweenness centrality is " 0 ". It confirms that the recommendations in the fifth stage are novelties that have not been institutionalized through coercive, normative, and mimetic elements.

\section{Conclusion}

The results of the seven stages of SSM show that institutional divergence in the context of digital-hybrid bureaucracy in Indonesia will still need a long time to progress because it is influenced by various causes, such as differences in competencies in information technology, age, professional background, individual creativity, and patronistic culture that tends to resist changes. The impact of normative and mimetic mechanisms on the three principles of DWB is evident at micro, meso, and macro levels. At the micro level, various causes of differences result in the low competence of bureaucrats, thus the achievement of intelligent efficiency does not reach the ability to analyze real time big data in making decisions. This condition causes the failure of sizing up objectivity because governance is not based on digital data. Meanwhile, the condition of non-autonomous big data that still experiences a human touch is not sufficient to shift rational to remotely rational. Digitalization is still positioned as a different way than paper-based management. Therefore, it has not arrived at DEG such as reintegration, needbased holism, and digitalization (Dunleavy et al. 2006; Margetts and Dunleavy 2013).

At the meso level, normative and mimetic divergences affect the performance of actors as a group. Ironically, actors who are not directly involved, such as writers and revisers who are outside the bureaucracy, are actually have higher performance than PCM. This fact is supported by an organizational narrative that technically does not position mastering digital competence as an urgency in institutional rules. The PCM perceives that digital dynamics needs to be mastered by CIO only. It provides more opportunities to CIO to master digital competence, hence their best performance among other groups.

At the macro level, the absence of institutional rules at the ministerial level on how bureaucrats should adapt to digital transformation has made the direction of transformation experiences institutional divergence. Institutionally, there is no coercive push and obligations to have certain competencies or to what extent the transformation must be carried out. Referring to the map of text network at the macro level, without clear and binding rules of digital transformation, the institutional divergence at the meso level will remain diverse.

In regard to the dynamics at the micro, meso, and macro levels, institutional divergence of digital item bank is in the form of hybridization. Normative mechanisms on the area of 'beliefs' indicate that the implementation of the management is based on hierarchy, a feature of the TPA. The legitimacy of leaders is firmly rooted, substituting for the absence of rules at the meso and macro levels in the context of digital transformation. In the area of 'design', the strategy used takes a participatory form through an online-based application that involves various stakeholders. The involvement of external parties at a micro level is represented by writers and revisers working as teachers and faculty members who, in public administration, can be categorized as collaborative government, a characteristic of Post NPM. In the area of "control", the monitoring of organizational performance based on input and output is evident from the TNA results at the macro and meso levels, showing the pattern of NPM. The combination of TPA, NPM, and Post NPM proves that the institutional divergence of digital item bank is fully hybrid (De Waele et al. 2015).

The implementation of SSM based on multi-method clearly emphasizes the analysis of the complexity of the problem owner in dealing with the problem. The naming 
of multi-method refers to Mingers (2001) and Stephens et al. (2009) due to the large structure of methodology using SSM by utilizing TNA and SNA as supporting methods. TNA that is based on semantic logic is able to describe word formations whose meanings represent the real world. Meanwhile, SNA provides legitimacy for the shift in the role of social actors in the digital world that cannot be described visually and systemically using interview data only.

Supplementary Information The online version contains supplementary material available at https://doi. org/10.1007/s11213-021-09579-4.

\section{References}

Al-Kaabi H (2020) Evaluation of the Vocational Training System in Qatar's Public Sector. Thesis. Cardiff Metropolitan University

Beckert J (2010) Institutional isomorphism revisited: convergence and divergence in institutional change. Sociol Theory 28(2):150-166. http://www.jstor.com/stable/25746221. Accessed 04 Aug 2020

Berg LN, Pinheiro R (2016) Handling different institutional logics in the public sector: comparing management in Norwegian universities and hospitals. Res Sociol Organ 45:146-168. https://doi.org/10. 1108/S0733-558X20150000045018

Borgatti SP, Brass DJ, Halgin DS (2014) Social network research: confusions, criticisms, and controversies. Res Sociol Organ 40:1-29. https://doi.org/10.1108/S0733-558X(2014)0000040001

Breit E, Fossest $\varnothing 1$ K, Andreassen TA (2018) From pure to hybrid professionalism in post-NPM activation reform: the institutional work of frontline managers. J Prof Organ 5(3):28-44. https://doi.org/ 10.1093/jpo/jox013

Brocklesby J (1995) Intervening in the cultural constitution of systems-methodological complementarism and other visions for systems research. J Oper Res Soc 46(11):1285-1298. https://doi.org/10. 1057/jors.1995.178

Checkland P (2000) Soft systems methodology: a thirty year retrospective. Syst Res Behav Sci 17:1158. https://doi.org/10.1002/1099-1743(200011)17:1+<::aid-sres374>3.0.co;2-o

Checkland P, Poulter J (2006) Learning for Action: A Short Definitive Account of Soft Systems Methodology and its use for Practitioners. John Wiley \& Sons Ltd, Teachers and Students

Correia T, Denis JL (2016) Hybrid management, organizational configuration, and medical professionalism: evidence from the establishment of a clinical directorate in Portugal. BMC Health Serv Res 16(2). https://doi.org/10.1186/s12913-016-1398-2

Curtis S (2019) Digital transformation-the silver bullet to public service improvement? Public Money Manag 39(5):322-324. https://doi.org/10.1080/09540962.2019.1611233

Danowski JA, Riopelle K (2020) Correction to: scaling constructs with semantic networks (quality and quantity, (2019), 53, 5, (2671-2683), 10.1007/s11135-019-00879-5). Qual Quant 54(1):235-247. https://doi.org/10.1007/s11135-019-00959-6

De Waele L, Berghman L, Matthyssens P (2015) Defining hybridity and hybrid contingencies in public organizations: an alternative conceptual model. Stud Public Non-Profit Gov 4:113-154. https://doi. org/10.1108/S2051-663020150000004005

Diegel W, Moritz A, Block JH, Botsari A, Lang F, Krämer-Eis H (2020) Measuring Venture Capital Sentiment in Europe. In FGF Studies in Small Business and Entrepreneurship. https://doi.org/10. 1007/978-3-030-17612-9_6

DiMaggio PJ, Powell WW (1983) The Iron cage revisited: institutional isomorphism in organizational fields. Am Sociol Rev 48(2):147-160. http://www.jstor.org/stable/2095101. Accessed 04 Aug 2020

Donina D, Paleari S (2019) New public management: global reform script or conceptual stretching? Analysis of university governance structures in the Napoleonic administrative tradition. High Educ 78(2):193-219. https://doi.org/10.1007/s10734-018-0338-y

Dunleavy P, Margetts H, Bastow S, Tinkler J (2006) Public management research association new public management is dead: long live digital-era governance. J Public Admin Res Theory 16(3):467494. http://www.jstor.org/stable/3840393. Accessed 10 Sep 2020 
Dwivedi P, Shankar RT, Meghana B, Sushaini H, Sudeep BR, Pooja MR (2021) Designing an adaptive question Bank and question paper generation management system. Adv Intell Syst Comput 1133:965-973. https://doi.org/10.1007/978-981-15-3514-7_72

Ediyono (2013) Penyempurnaan Proses Implementasi Evaluasi Diri Sekolah Dalam rangka Penjaminan dan Peningkatan Mutu Pendidikan: Sebuah Aplikasi Riset Tindakan Berbasis SSM. Master Thesis. Faculty of Social and Political Sciences. University of Indonesia. http://lontar.ui.ac.id/detail?id= 20348762\&lokasi=loka

Garg S, Norman GJ (2021) Impact of COVID-19 on health economics and Technology of Diabetes Care: use cases of real-time continuous glucose monitoring to transform health care during a global pandemic. Diabetes Technol Ther 23(S1):S15-S20. https://doi.org/10.1089/dia.2020.0656

Gaus N, Sultan S, Basri M (2017) State bureaucracy in Indonesia and its reforms: an overview. Int J Public Adm 40(8):658-669. https://doi.org/10.1080/01900692.2016.1186179

Gebreiter F, Hidayah NN (2019) Individual responses to competing accountability pressures in hybrid organisations: the case of an English business school. Account Audit Account J 32(3):727-749. https://doi.org/10.1108/AAAJ-08-2017-3098

Glaser BG, Anselm LS (2017) The discovery of grounded theory strategies for qualitative research. https://doi.org/10.4324/9780203793206

Gulbrandsen M (2011) Research institutes as hybrid organizations: central challenges to their legitimacy. Policy Sci 44(3):215-230. https://doi.org/10.1007/s11077-011-9128-4

Hadiyanto W (2013) Penyempurnaan Kebijakan Lembaga Penyiaran Publik Televisi Republik Indonesia- TVRI, Aplikasi Riset Tindakan Berbasis SSM. Master Thesis. Faculty of Social and Political Sciences. University of Indonesia. http://lontar.ui.ac.id/detail?id=20348952\&lokasi=lokal

Hardjosoekarto S (2012) Construction of social development index as a theoretical research practice in action research by using soft systems methodology. Syst Pract Action Res 25(6):493-509. https:// doi.org/10.1007/s11213-012-9237-9

Hardjosoekarto S, Yovani N, Santiar L (2013) Institutional strengthening for the role of mass Media in Disaster Risk Reduction in Japan and Indonesia: an application of SSM-based action research. Syst Pract Action Res 27(3):227-246. https://doi.org/10.1007/s11213-013-9282-Z

Heeks R (2002) iGovernment: working paper series. In eGovernment in Africa: promise and practice (no. 13). University of Manchester, precinct Centre. http://idpm.man.ac.uk/wp/igov/index.htm. Accessed 20 Oct 2020

Hildebrandt SA, Eom M (2011) Teacher professionalization: motivational factors and the influence of age. Teach Teach Educ 27(2):416-423. https://doi.org/10.1016/j.tate.2010.09.011

Kareborn (2004) Basic principles of SSM modeling: an examination of CATWOE from a soft perspective. Problemy Peredachi Informatsii 40(2):50-62. https://doi.org/10.1023/B:SPAA.0000018903. 18767.18

Khodachek I, Timoshenko K (2018) Russian central government budgeting and public sector reform discourses: paradigms, hybrids, and a "Third Way". Int J Public Adm 41(5-6):460-477. https://doi.org/ 10.1080/01900692.2017.1383417

Kotiadis K, Tako AA, Rouwette EAJA, Vasilakis C, Brennan J, Gandhi P, Wegstapel H, Sagias F, Webb P (2013) Using a model of the performance measures in soft systems methodology (SSM) to take action: a case study in health care. J Oper Res Soc 64(1):125-137. https://doi.org/10.1057/jors. 2012.21

Kusumastuti R (2013) Membangun Keunggulan Bersaing Melalui Dual Ambidexterity: Aplikasi Multi Metodologi Cognitive Map dan SSM kontinum Dual Imperatives. Doctoral Dissertation. Faculty of Social and Political Sciences. University of Indonesia. http://lontar.ui.ac.id/detail?id=20350869\& lokasi=lokal

Larrán M, Herrera J, Andrades FJ (2015) Measuring the linkage between strategies on sustainability and institutional forces: an empirical study of Spanish universities. J Environ Plan Manag 59(6):967992. https://doi.org/10.1080/09640568.2015.1050485

Margetts H, Dunleavy P (2013) The second wave of digital-era governance: a quasi-paradigm for government on the web. Philos Trans R Soc A Math Phys Eng Sci 371(1987):20120382. https://doi. org/10.1098/rsta.2012.0382

Matsuoka R, Akazawa H, Kodera S, Komuro I (2020) The dawning of the digital era in the management of hypertension. Hypertens Res 43(11):1135-1140. https://doi.org/10.1038/s41440-020-0506-1

Mehra A, Kilduff M, Brass DJ (2001) The social networks of high and low self-monitors: implications for workplace performance. Adm Sci Q 46(1):121-146. https://doi.org/10.2307/2667127

Meilani NL, Hardjosoekarto S (2020) Digital weberianism bureaucracy: alertness and disaster risk reduction (DRR) related to the Sunda Strait volcanic tsunami. Int J Disaster Risk Reduction 51:101898. https://doi.org/10.1016/j.ijdrr.2020.101898 
Mingers J (2001) Combining IS research methods: towards a pluralist methodology. Inf Syst Res 12(3):240-259. https://doi.org/10.1287/isre.12.3.240.9709

Möllers N (2021) Making digital territory: cybersecurity, techno-nationalism, and the moral boundaries of the state. Sci Technol Hum Values 46(1):112-138. https://doi.org/10.1177/0162243920904436

Muellerleile C, Robertson SL (2018) Digital Weberianism: bureaucracy, information, and the technorationality of neoliberal capitalism. Indiana J Global Legal Stud 25(1):187. https://doi.org/10.2979/ indjglolegstu.25.1.0187

Muliawaty L, Alamsyah K, Salamah U, Maylawati DS (2019) The concept of big data in bureaucratic service using sentiment analysis. Int J Sociotechnol Knowl Dev 11(3):1-13. https://doi.org/10. 4018/IJSKD.2019070101

Muluk MRK, Danar OR, Rahmawati L (2019) Community participation and development planning in local government level: a study on the formulation of Batu City medium-term development plan. BISNIS \& BIROKRASI: Jurnal Ilmu Administrasi dan Organisasi 26(3):1. https://doi.org/10. 20476/jbb.v26i3.11145

OECD (2018) PISA 2018 released financial literacy items. August, 1-27. http://www.oecd.org/pisa/test/

Pakpahan R (2016) Computer based national exam model: its benefits and barriers. Jurnal Pendidikan Dan Kebudayaan 1(1):19-35. https://media.neliti.com/media/publications/124980-none-a7dd8e51. pdf. Accessed 25 Apr 2021

Permatasari YI, Hardjosoekarto S, Salomo RV (2019) Institutional transformation of public private partnership to ensure low transaction costs: case study of infrastructure provision at the Ministry of Public Works and Housing of the Republic of Indonesia. Syst Pract Action Res 33(2):149-165. https://doi.org/10.1007/s11213-019-09485-w

Pinora JA (2014) Implementasi SSM dalam Perkembangan Penyelidikan Intelijen Guna Menghadapi Ancaman Jaringan Terorisme di Indonesia. Master Thesis. Faculty of Social and Political Sciences. University of Indonesia. http://lontar.ui.ac.id/detail?id=20414093\&lokasi=lokal

Pollack J (2007) The changing paradigms of project management. Int J Proj Manag 25(3):266-274. https://doi.org/10.1016/j.ijproman.2006.08.002

Reynolds M, Holwell S (2010) Systems approaches to managing change: a practical guide. In Systems Approaches to Managing Change: A Practical Guide. https://doi.org/10.1007/978-1-84882-809-4

Rogiers P, Viaene S, Leysen J (2020) The digital future of internal staffing: a vision for transformational electronic human resource management. Intell Syst Account Financ Manag 27(4):182-196. https:// doi.org/10.1002/isaf.1481

Sari AM, Hidayanto AN, Purwandari B, Budi NFA, Kosandi M (2018) Challenges and issues of E-participation implementation: a case study of e-complaint Indonesia. Proceedings of the 3rd international conference on informatics and computing, ICIC 2018, 1-6. https://doi.org/10.1109/IAC. 2018.8780467

Segev E (2020) Textual network analysis: detecting prevailing themes and biases in international news and social media. Sociol Compass 14(4):1-14. https://doi.org/10.1111/soc4.12779

Simonet D (2015) Post-NPM reforms or administrative hybridization in the French health care system? Int J Public Adm 38(9):672-681. https://doi.org/10.1080/01900692.2014.955195

Sofyani H, Akbar R, Ferrer RC (2018) 20 years of performance measurement system (PMS) implementation in indonesian local governments: why is their performance still poor? Asian J Bus Account 11(1):151-184. https://doi.org/10.22452/ajba.vol11no1.6

Stephens J, Barton J, Haslett T (2009) Action research: its history and relationship to scientific methodology. Syst Pract Action Res 22(6):463-474. https://doi.org/10.1007/s11213-009-9147-7

Sulistiyani E, Susanto TD (2018) Change management methodology for e-government project in developing countries: a conceptual model. Proceedings of the 3rd international conference on informatics and computing, ICIC 2018, 1-5. https://doi.org/10.1109/IAC.2018.8780500

Surjana O, Siswoyo M, Dedy ASK (2020) Bureaucratic reform and empowerment of state civil apparatus in the face of the industrial revolution 4.0 (pp. 2608-2611). https://doi.org/10.5373/JARDCS/ V12I2/S20201310

Tian X, Christensen T (2020) Ambiguous hybridity? Main features of China's service-oriented government reform. Int J Public Sect Manag 33(4):419-433. https://doi.org/10.1108/IJPSM-09-2019-0241

Tsoi HL (2004) Logical soft systems methodology for education Programme development. Issues Inf Sci Inf Technol 1:1027-1035. https://doi.org/10.28945/796

Turner M, Prasojo E, Sumarwono R (2019) The challenge of reforming big bureaucracy in Indonesia. Policy Stud 0(0): 1-19. https://doi.org/10.1080/01442872.2019.1708301

Ugyel L (2014) Explaining hybridity in public administration: an empirical case of bhutan's civil service. Public Adm Dev 34(2):109-122. https://doi.org/10.1002/pad.1685 
Van der Aalst WMP (2007) Exploring the CSCW spectrum using process mining. Adv Eng Inform 21(2):191-199. https://doi.org/10.1016/j.aei.2006.05.002

Weber M (1978) Economy and society: an outline of interpretive sociology. Sociology 3(3):448-449. https:// doi.org/10.1177/003803856900300342

Wilopo (2013) Pembaruan Kelembagaan dan Tata Kelola dalam Rangka Perbaikan Pelayanan ICT USO. Doctoral Dissertation. Faculty of Social and Political Sciences. University of Indonesia. http://lontar.ui.ac.id/detail?id=20364578\&lokasi=lokal

Wilson B (2010) Soft systems methodology for conceptual modeling. In Conceptual Modeling for Discrete-Event Simulation. https://doi.org/10.1201/9781439810385-p3

Xiaolong T, Christensen T (2019) Beyond NPM to post-NPM? A study of China's government reforms over the past 40 years. Am Rev Public Adm 49(7):855-865. https://doi.org/10.1177/0275074019 849122

Xu S, Du W, Wang C, Liu D (2017) The library big data research: status and directions. Int J Softw Innov 5(3):77-88. https://doi.org/10.4018/IJSI.2017070106

Yildızcan C, Bayraktar U (2019) The empowerment of Turkish governors within hybrid settings of public administration. Mediterr Polit 24(3):356-375. https://doi.org/10.1080/13629395.2017.1398889

Yovani N (2013) Transfer Teknologi sebagai Konstruksi Sosial: Sebuah Tesis awal yang diperoleh dari Perusahaan Afiliasi Jepang dan Perusahaan Lokal Komponen Otomotif dengan menggunakan SSM. Doctoral Dissertation. Faculty of Social and Political Sciences. University of Indonesia. http://lontar. ui.ac.id/detail?id=20329026\&lokasi=lokal

Publisher's Note Springer Nature remains neutral with regard to jurisdictional claims in published maps and institutional affiliations. 